\title{
ADMINISTRACIÓN ESTRATÉGICA: EL IMPACTO DE LAS NORMAS DE GOBIERNO CORPORATIVO EN EL DESEMPEÑO EMPRESARIAL BOLIVIANO
}

\section{Laura Constanza García Sobral}

\section{RESUMEN}

El Gobierno Corporativo constituye un conjunto de principios y normas diseñadas para regular las relaciones internas de una empresa, en miras a lograr una eficiente gestión institucional. Su implementación ha generado mayor transparencia en los mercados financieros, ha brindado seguridad jurídica a socios y administradores de empresas, y ha demostrado incidir positivamente en el compromiso institucional con los grupos de interés vinculados a la actividad empresarial. Múltiples estudios a nivel mundial reflejan la existencia de una relación positiva entre la implementación de estas normas y los resultados empresariales. En ese contexto, el presente trabajo de investigación pretende servir como base para medir la vinculación positiva entre el desempeño empresarial y la aplicación de normas de gobierno corporativo, como mecanismo estratégico de control interno en empresas bolivianas. Efectuando un análisis cuantitativo con información recabada de la Encuesta Empresarial elaborada en Bolivia por el Banco Mundial en el año 2017, el presente estudio permitió identificar que la desconcentración del capital social, la experiencia efectiva de los ejecutivos de las empresas, y los bonos o retribuciones económicas que puedan percibir, poseen una incidencia positiva y significativa en el desempeño de las organizaciones.

Palabras Clave: Gobierno Corporativo, Administración Estratégica, Desempeño Empresarial.

DOI: 10.23881/idupbo.020.2-7e 